\title{
Sistem Informasi Pelayanan Kesehatan Online Berbasis Web Pada PMI Kabupaten Purbalingga
}

\author{
Ryan Latifahul Khasanah ${ }^{1}$, Chandra Kesuma ${ }^{2}$, Ragil Wijianto ${ }^{3}$ \\ Sistem Informasi, Universitas BSI \\ Sistem Informasi, AMIK BSI Pontianak \\ Sistem Informasi, STMIK Nusa Mandiri Jakarta \\ riyanlat0804@bsi.ac.id, Chandra.cka@bsi.ac.id, ragil.rgw@nusamandiri.ac.id
}

\begin{abstract}
The Indonesian Red Cross (PMI) is an institution engaged in the field of health and social humanity with one of its main tasks is to provide health services and community welfare. The existence of PMI Purbalingga is very helpful to the community in terms of health and welfare services, such as blood donation, blood donation, medical examination and disaster management. However, the process of health services is still done manually, including the process of admission of outpatients at the PMI clinic. This often makes the patient queue for a long time to register. Blood donor information and stock of available bloodbags can not be accessed easily by the public. From these problems the authors conclude that the PMI Purbalingga need a website as a means to improve public access to health service information in PMI Purbalingga. In making the website of this online health service, the authors make observations, interviews and search various references from journals and articles on the internet. This website becomes the right solution to the problems that exist because the website can reach many people and can be accessed easily whenever and wherever.
\end{abstract}

\section{Keywords_Information Systems, Online Health Services, Indonesian Red Cross}

\begin{abstract}
Abstrak - Palang Merah Indonesia (PMI) adalah lembaga yang bergerak di bidang kesehatan dan sosial kemanusiaan dengan salah satu tugas pokoknya yaitu menyediakan pelayanan kesehatan dan kesejahteraan masyarakat. Keberadaan PMI Kabupaten Purbalingga sangat membantu masyarakat dalam hal pelayanan kesehatan dan kesejahteraan, seperti melakukan donor darah, mendapatkan donor darah, pemeriksaan kesehatan serta penanggulangan bencana. Namun proses pelayanan kesehatan masih dilakukan secara manual, termasuk proses pendaftaran pasien rawat jalan di klinik PMI. Hal ini seringkali membuat pasien harus mengantri lama untuk melakukan pendaftaran. Informasi donor darah dan stok kantung darah yang tersedia pun belum bisa diakses secara mudah oleh masyarakat. Dari permasalahan tersebut penulis menyimpulkan bahwa PMI Kabupaten Purbalingga memerlukan sebuah website sebagai sarana untuk meningkatkan akses masyarakat terhadap informasi pelayanan kesehatan di PMI Kabupaten Purbalingga. Dalam pembuatan website pelayanan kesehatan online ini, penulis melakukan pengamatan, wawancara dan mencari berbagai referensi dari jurnal dan artikel di internet. Website ini menjadi solusi yang tepat atas permasalahan yang ada dikarenakan website dapat menjangkau banyak orang serta dapat diakses dengan mudah kapanpun dan dimanapun.
\end{abstract}

\section{Kata Kunci-Sistem Informasi, Pelayanan Kesehatan Online, PMI}

\section{A. PENDAHULUAN}

Teknologi informasi di era sekarang tidak lagi dianggap sebagai hal yang baru. Dalam perkembangannya teknologi informasi telah merambah semua bidang kehidupan, termasuk bidang kesehatan. Salah satu upaya mewujudkan status kesehatan masyarakat yang optimal adalah dengan meningkatkan akses masyarakat terhadap pelayanan kesehatan dasar (Syukron dan Hasan, 2015:28).

Palang Merah Indonesia (PMI) sebagai salah satu lembaga yang bergerak di bidang kesehatan dan sosial kemanusiaan saat ini telah berdiri di 33 provinsi, 371 kabupaten/kota dan 2.654 kecamatan di Indonesia (sumber: http://www.pmi.or.id/). Sejalan dengan salah satu tugas pokok PMI yaitu menyediakan pelayanan kesehatan dan kesejahteraan masyarakat, maka PMI mendirikan rumah sakit dan klinik sebagai tempat pelayanan kesehatan. Salah satunya yaitu Klinik PMI Kabupaten Purbalingga.

Keberadaan PMI Kabupaten Purbalingga sangat membantu masyarakat dalam hal pelayanan kesehatan. Selain sebagai tempat untuk mendonorkan darah dan mendapatkan donor darah, masyarakat bisa mendapatkan pemeriksaan kesehatan melalui klinik PMI. Apalagi Klinik PMI Kabupaten Purbalingga 
menerima pasien umum maupun pasien peserta BPJS, sehingga dapat membantu masyarakat yang kurang mampu untuk mendapatkan pelayanan kesehatan.

Namun dalam praktiknya, informasi pelayanan kesehatan di PMI Kabupaten Purbalingga masih belum terpublikasi secara luas. Selain itu proses pelayanan kesehatan masih dilakukan secara manual, termasuk proses pendaftaran pasien rawat jalan. Hal ini seringkali membuat pasien harus mengantri lama untuk melakukan pendaftaran. Informasi donor darah dan stok kantung darah yang tersedia pun belum bisa diakses secara mudah oleh masyarakat, padahal kantung darah menjadi salah satu hal yang sangat penting dalam menunjang pengobatan pasien yang membutuhkan. Maka diharapkan dengan dibuatnya website mengenai informasi pelayanan kesehatan online ini dapat meningkatkan akses masyarakat terhadap informasi pelayanan kesehatan di PMI Kabupaten Purbalingga. Untuk itulah penulis mengambil judul skripsi. "Sistem Informasi Pelayanan Kesehatan Online Berbasis Web Pada Pmi Kabupaten Purbalingga".

\section{B. TINJAUAN PUSTAKA}

\section{Sistem Informasi}

Menurut Leitch dalam Mujiati dan Sukadi (2016:12) menyatakan bahwa:Sistem informasi adalah suatu sistem di dalam suatu organisasi yang mempertemukan kebutuhan pengolahan transaksi harian, mendukung operasi, bersifat manajerial dan kegiatan strategis dari suatu organisasi dan menyediakan pihak luar tertentu dengan laporan-laporan yang diperlukan.

\section{Pelayanan Kesehatan}

Menurut Levey dan Loomba dalam Raja dkk (2015:64) menyatakan bahwa:Pelayanan kesehatan adalah upaya yang diselenggarakan sendiri atau secara bersamasama dalam suatu organisasi untuk memelihara dan meningkatkan kesehatan dan mencegah dan menyembuhkan penyakit serta memulihkan kesehatan perorangan, keluarga, kelompok, ataupun masyarakat.

\section{Website}

Menurut Riyadi dalam Josi (2016:1) menyatakan bahwa:Website atau situs dapat diartikan sebagai kumpulan halaman yang menampilkan informasi data teks, data gambar diam atau gerak, data animasi, suara, video dan gabungan dari semuanya baik yang bersifat statis maupun dinamis yang membentuk suatu rangkaian bangunan yang saling terkait dimana masing-masing dihubungkan dengan jaringan-jaringan halaman (hyperlink).

\section{Bootstrap Versi 4.0.0}

Menurut Husein dalam Josi (2016:2) menyatakan bahwa:Bootstrap adalah framework ataupun tools untuk membuat aplikasi web ataupun website yang bersifat responsive secara cepat, mudah dan gratis. Kata responsive disini berarti bahwa tampilan web lebar dan susunan isinya dapat berubah secara otomatis sesuai dengan lebar layar yang menampilkannya.

\section{Codelgniter Versi 3.1.8}

Menurut Suharsana dkk (2016:22), "Codelgniter adalah sebuah framework yang digunakan untuk membuat sebuah aplikasi berbasis web yang disusun dengan menggunakan bahasa PHP".

\section{ERD (Entity Relationship Diagram)}

Entity Relationship Diagram (ERD) merupakan gambaran data yang dimodelkan dalam suatu diagram yang digunakan untuk mendokumentasikan data dengan cara menentukan apa saja yang terdapat tiap entity dan bagaimana hubungan antara entity satu dengan lainnya (Rahmayu, 2016:34).

\section{LRS (Logical Record System)}

Menurut Dhanta dalam Junianto dan Primaesha (2015:444), "LRS (Logical Record System) adalah representasi dari struktur record-record pada tabel-tabel yang terbentuk dari hasil antar himpunan entitas". Sedangkan menurut Frieyadie dalam Rahmayu (2015:162), "LRS merupakanhasil dari pemodelanEntity Relational Ship (ER) beserta atributnya sehingga bisaterlihat hubunganhubungan antar entitas".

\section{UML (Unifield Modelling Language)}

Menurut Fowler dalam Syukron dan Hasan (2015:30) menyatakan bahwa, "Unifield Modelling Language (UML) adalah keluarga notasi grafis yang didukung oleh meta model tunggal, yang membantu pendeskripsian dan desain sistem perangkat lunak, khususnya sistem yang dibangun dengan menggunakan pemrograman berorientasi objek (OOP)".Diagram-diagram dalam UML antara lain:

a. Use case diagram

Use case diagram mendeskripsikan interaksi tipikal antara para pengguna sistem dengan sistem itu sendiri, dengan memberi sebuah narasi tentang bagaimana sistem tersebut digunakan.

b. Activity diagram 
Activity diagram adalah teknik untuk menggambarkan logika prosedural, proses bisnis dan proses kerja. Dalam beberapa hal, diagram ini memainkan peran mirip sebuah diagram alir, tetapi perbedaan prinsip antara diagram ini dan notasi diagram alir adalah diagram ini mendukung behavior paralel.

c. Class diagram

Class diagram menggambarkan jenis objek dalam sistem dan berbagai jenis hubungan statis yang ada diantara mereka. Class diagram juga menunjukkan sifat-sifat dan operasi dari sebuah kelas dan kendala yang berlaku untuk cara objek yang terhubung.

d. Sequence diagram

Sequence diagram menggambarkan interaksi antar objek didalam dan di sekitar sistem (termasuk pengguna, display dan sebagainya) berupa message yang digambarkan terhadap waktu. Sequence diagram biasa digunakan untuk menggambarkan skenario atau langkah-langkah yang dilakukan sebagai respon dari sebuah event untuk menghasilkan output tertentu.

e. Component diagram

Component diagram digunakan untuk menggambarkan organisasi dari sistem dan ketergantungan dari komponen perangkat lunak dalam sistem, dapat juga digunakan untuk menunjukkan bagaimana kode program dibagi menjadi modul-modul atau komponen.

f. Deployment diagram

Deployment diagram mendeskripsikan arsitektur fisik dalam node untuk perangkat lunak sistem. Komponen perangkat lunak, processor, dan peralatan lain yang membangun arsitektur sistem secara run-time.

\section{Black Box Testing}

Menurut Fatta dalam Setiyawati dan Sardiarinto (2016:37) menyatakan bahwa, "black box testing merupakan pengujian yang dilakukan dengan menjalankan atau mengeksekusi unit sesuai dengan proses sistem yang diinginkan". Sedangkan menurut Pressman dalam Taufik dan Ermawati (2017:3), "black box testing merupakan pengujian yang memungkinkan software engineer mendapatkan serangkaian kondisi input yang sepenuhnya menggunakan semua persyaratan fungsional untuk suatu program". 10.Penelitian Terkait
Menurut Sundari (2016) dalam jurnalnya yang berjudul "Sistem Informasi Pelayanan Puskesmas Berbasis Web", dampak dari perkembangan pelayanan elektronik di dalam lingkungan publik dapat terlihat melalui kehadiran electronic service (E-service). Pembuatan e-service dalam bentuk website pada tempat pelayanan kesehatan puskesmas memberikan alternatif pemecahan masalah dalam sistem registrasi dan pengambilan nomor antrian pasien. Dengan web ini pasien dapat lebih mudah mengakses jadwal dokter dan informasi lainnya terkait pelayanan kesehatan di puskesmas. Website ini juga dapat meningkatkan efektifitas dan efisiensi dari segi pelayanan, waktu dan biaya pada puskesmas.

Sedangkan menurut Purnama and Hasan (2016) dalam jurnalnya yang berjudul "Perancangan Sistem Informasi Inventori Darah Berbasis Web pada Palang Merah Indonesia Cabang Bantul", minimnya informasi mengenai ketersediaan kantong darah di PMI Cabang Bantul mengakibatkan proses pencarian kantong darah memakan waktu yang cukup lama. Selain itu PMI Cabang Bantul hanya menunggu pendonor datang ke markas untuk melakukan donor darah dan tidak ada kegiatan proaktif untuk memberikan informasi kepada calon pendonor. Maka dengan adanya website akan memberikan kemudahan kepada masyarakat untuk mendapatkan informasi seperti ketersediaan stok darah, pemesanan darah, pendaftaran calon pendonor secara online, serta memberikan kemudahan bagi pihak PMI dalam membuat laporan data darah masuk dan keluar.

Dari dua penelitian diatas, penulis menyimpulkan bahwa website sangat diperlukan dalam rangka meningkatkan kualitas pelayanan di unit-unit pelayanan kesehatan. Apalagi PMI Kabupaten Purbalingga menyediakan layanan pemeriksaan kesehatan seperti puskesmas sekaligus layanan donor darah yang umum dilakukan oleh PMI. Untuk meningkatkan layanan pemeriksaan kesehatan maka salah satu yang bisa dilakukan adalah memberikan sarana pendaftaran pasien rawat jalan secara online sekaligus menampilkan informasi jadwal dokter. Hal ini untuk mengurangi antrian pasien di bagian pendaftaran. Sedangkan untuk meningkatkan layanan donor darah maka diperlukan media informasi unit donor darah seperti informasi donor darah dan stok kantung darah yang tersedia. 
Namun dari dua penelitian sebelumnya website belum menyediakan fasilitas konsultasi secara online antara masyarakat dengan dokter. Maka pada website ini penulis menambahkan fitur konsultasi online dimana masyarakat dapat mengajukan pertanyaan melalui website dan dokter akan memberikan jawaban berupa diagnosa sementara.

\section{METODE PENELITIAN}

1. Teknik Pengumpulan Data

Teknik pengumpulan data yang dilakukan oleh penulis antara lain:

a. Observasi

Penulis melakukan pengamatan langsung di Unit Transfusi Darah, Markas dan Klinik PMI Kabupaten Purbalingga mengenai pelayanan kesehatan yang ada, seperti prosedur pendaftaran pasien rawat jalan, prosedur donor darah dan prosedur permintaan kantung darah.

b. Wawancara

Wawancara dilakukan dengan mengajukan pertanyaan terhadap pegawai PMI Kabupaten Purbalingga mengenai profil lembaga dan pelayanan kesehatan yang tersedia.

c. Studi pustaka

Studi pustaka dilakukan dengan mencari, membaca dan mempelajari berbagai referensi dari buku, jurnal maupun artikel internet terkait judul skripsi yang diambil.

2. Model Pengembangan Sistem

Dalam mengembangkan sistem informasi pelayanan kesehatan online ini penulis menggunakan model Waterfall, dimana menurut Rosa dan Shalahuddin dalam Dermawan dan Hartini (2017:143) tahap pengembangan sistemnya sebagai berikut:

a. Analisa kebutuhan perangkat lunak

Pada tahap ini penulis mengkaji sistem seperti apa yang hendak dibuat berdasarkan hasil pengamatan di lapangan dan wawancara langsung ke pegawai PMI Kabupaten Purbalingga. Analisa mengenai prosedur pelayanan kesehatan dilakukan agar nantinya website yang dihasilkan sesuai dengan kebutuhan dan harapan.

b. Desain

Pada tahap desain penulis menuangkan kebutuhan yang sudah dianalisa dalam bentuk desain antar muka dan desain struktur data. Penulis mendesain tampilan website yang terdiri dari halaman front end dan back end, serta mendesain tabel-tabel di database. Hal ini dilakukan agar kebutuhan sistem dapat diimplementasikan menjadi program pada tahap pengkodean.

c. Pembuatan kode program

Pembuatan kode-kode program dilakukan pada tahap ini agar desain yang telah dibuat dapat diimplementasikan menjadi program utuh untuk dapat dimanfaatkan sesuai tujuannya, antara lain menggunakan kode HTML, PHP, CSS dan Javascript.

d. Pengujian

Tools yang ada dalam website yang telah terbentuk perlu diuji agar bisa dipastikan bahwa keluaran yang dihasilkan sesuai dengan yang diinginkan dan juga untuk meminimalisir kesalahan (error). Pengujian yang dilakukan penulis menggunakan black box testing (pengujian kotak hitam).

e. Pendukung (support) atau pemeliharaan (maintenance)

Tidak menutup kemungkinan bahwa perangkat lunak yang telah dikirimkan kepada pengguna mengalami kesalahan (error) disebabkan perubahan kondisi dan kesalahan yang tidak terdeteksi pada saat pengujian. Untuk menangani hal tersebut maka perlu dilakukan tahap pendukung sehingga kesalahan yang ada dapat diperbaiki.

\section{HASIL DAN PEMBAHASAN}

1. Analisa KebutuhanSoftware

a. Kebutuhan Admin

A1. Admin dapat mengelola data member.

A2. Admin dapat mengelola data pasien.

A3. Admin dapat mengelola data antrian online.

A4. Admin dapat mengelola data dokter.

A5. Admin dapat mengelola data jadwal dokter.

A6. Admin dapat mengelola data konsultasi online.

A7. Admin dapat mengelola data pendonor.

A8. Admin dapat mengelola data stok darah.

A9. Admin dapat mengelola data jadwal donor darah.

A10.Admin dapat mengelola data permintaan mobil donor. 
A11.Admin dapat mengelola data administrator.

A12.Admin dapat mengelola data artikel.

A13. Admin dapat mengelola data berita. A14.Admin dapat mengelola data galeri. A15. Admin dapat mengelola data menu. A16. Admin dapat mengelola data profil PMI.

A17.Admin dapat mengelola data slider. A18. Admin dapat mengubah password.

A19.Admin dapat melihat laporanlaporan.

b. Kebutuhan Dokter

B1. Dokter dapat mengelola konsultasi online.

B2. Dokter dapat mengubah jadwal.

B3. Dokter dapat mengubah password.

c. Kebutuhan Member

C1. Member dapat mengelola data anggota keluarga.

C2. Member dapat melihat riwayat pendaftaran antrian rawat jalan online.

C3. Member dapat melakukan pendaftaran antrian rawat jalan online.

C4. Member dapat melakukan konsultasi online.

C5. Member dapat mengubah password.

d. Kebutuhan Pengunjung

D1. Pengunjung dapat membaca profil PMI.

D2. Pengunjung dapat membaca artikel.

D3. Pengunjung dapat melihat jadwal dokter.

D4. Pengunjung dapat melihat jadwal donor darah.

D5. Pengunjung dapat melihat stok darah terkini.

D6. Pengunjung dapat melakukan pendaftaran calon pendonor.

D7. Pengunjung dapat melakukan permintaan mobil donor.

D8. Pengunjung dapat membaca berita.

D9. Pengunjung dapat melihat galeri.

D10.Pengunjung dapat mendaftar sebagai member.
2. Use Case Diagram

a. Mengelola Halaman Admin

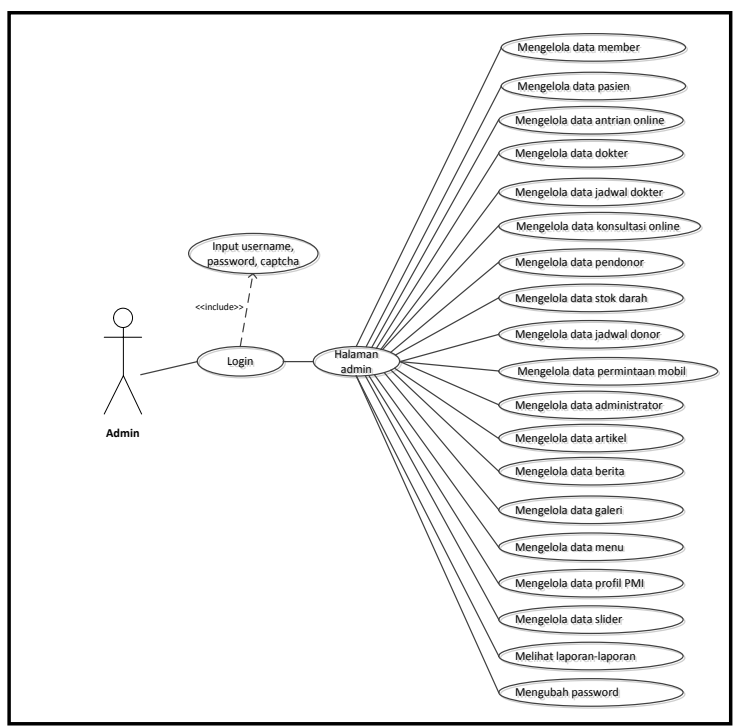

Gambar 1. Use Case Diagram Mengelola Halaman Admin

Tabel 1. Deskripsi Use Case Diagram Mengelola Halaman Admin

\begin{tabular}{|c|c|}
\hline Use Case Name & Mengelola Halaman Admin \\
\hline Requirem ents & A1 sampai A19 \\
\hline Goal & $\begin{array}{l}\text { Admin dapat melihat, menambahkan, mengedit } \\
\text { dan menghapus data-data }\end{array}$ \\
\hline Freconditions & Admin telah login \\
\hline Post-conditions & Data tampil, ters impan, ter update dan terhapus \\
\hline Failed End Conditions & $\begin{array}{l}\text { Gagal menampikan, menyimpan, mengupdate } \\
\text { dan menghapus }\end{array}$ \\
\hline Frim ary Actors & Admin \\
\hline Main Flow/Basic Path & $\begin{array}{l}\text { 1. Admin melihat data } \\
\text { 2. Admin menambahk an data } \\
\text { 3. Admin menyimpan data }\end{array}$ \\
\hline Invariant $A$ & 29. Admin mengedit data \\
\hline invariant $B$ & $2 \mathrm{~b}$. Admin menghapus data \\
\hline
\end{tabular}

b. Use Case Diagram Mengelola Halaman Member

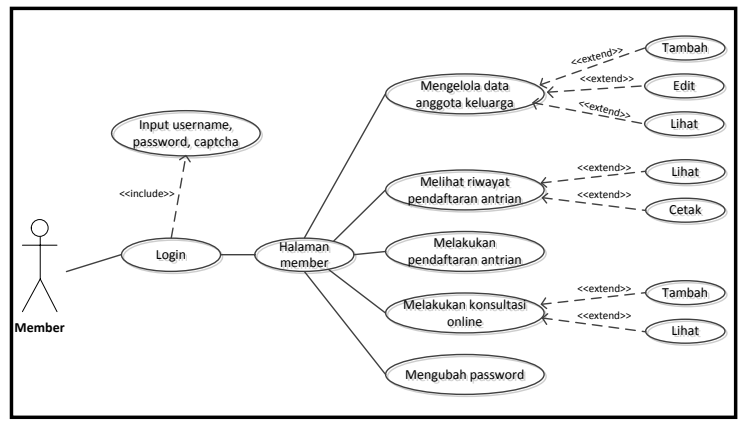

Gambar 2. Use Case Diagram Mengelola Halaman Member 
Tabel 2. Deskripsi Use Case Diagram Mengelola Halaman Member

\begin{tabular}{|c|c|}
\hline Use Case Name & \begin{tabular}{|l} 
Mengelola Halaman Mem ber \\
\end{tabular} \\
\hline Requirements & $\mathrm{C} 1, \mathrm{C} 2, \mathrm{C} 3, \mathrm{C} 4, \mathrm{C} 5$ \\
\hline Goal & $\begin{array}{l}\text { 1. Mem ber dapat menambah, mengedit, melihat data } \\
\text { anggota keluarga. } \\
\text { 2. Mem ber dapat melihat riwayat pendaftaran dan } \\
\text { mencetak bukti pendaftaran. } \\
\text { 3. Mem ber dapat melakukan pendaftaran antrian. } \\
\text { 4. Mem ber dapat menambah dan melihat konsultasi } \\
\text { online. } \\
\text { 5. Mem ber dapat mengubah password }\end{array}$ \\
\hline Freconditions & Mem ber telah login \\
\hline Fost-conditions & Data ters impan, terupdate dan tampil \\
\hline Failed End Conditions & Gagal menyimpan, mengupdate dan menampikan \\
\hline Fim ary Actors & Mem ber \\
\hline Main Flow/Basic Path & $\begin{array}{l}\text { 1. Mem ber menambah anggota k eluarga } \\
\text { 2. Mem ber melak ukan pendaftaran antrian } \\
\text { 3. Mem ber mencetak bukti pendaftaran }\end{array}$ \\
\hline Invariant $A$ & 29. Member mengedit data anggota keluarga \\
\hline Invariant $B$ & 2b. Member menambahkan pertanyaan konsultasi \\
\hline Invariant $C$ & 20. Member mengubah password \\
\hline
\end{tabular}

3. Activity Diagram Mengakses Halaman Pengunjung

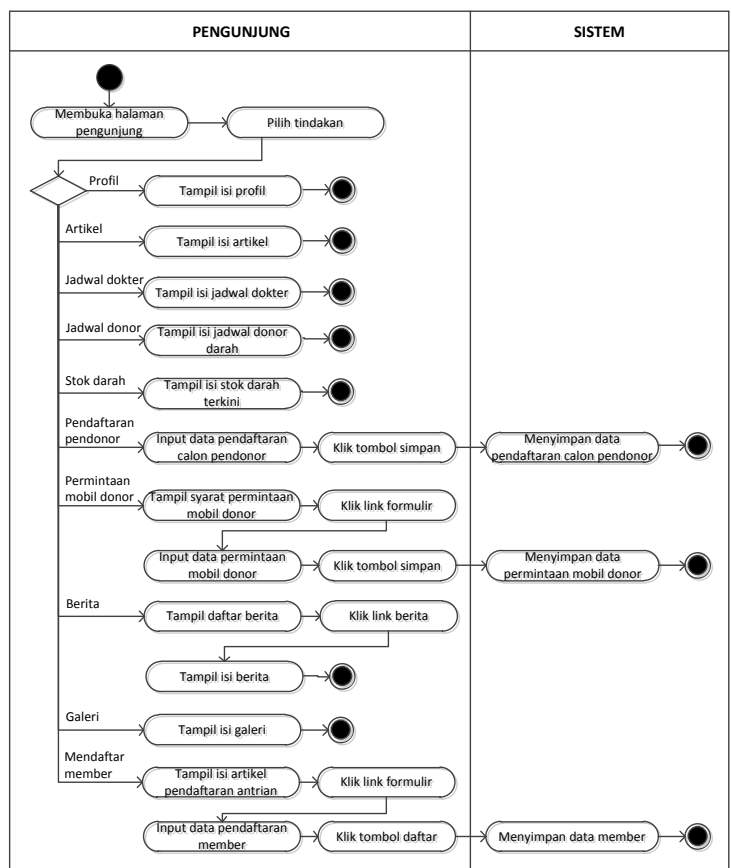

Gambar 3. Activity DiagramMengakses Halaman Pengunjung
4. Entity Relationship Diagram (ERD)

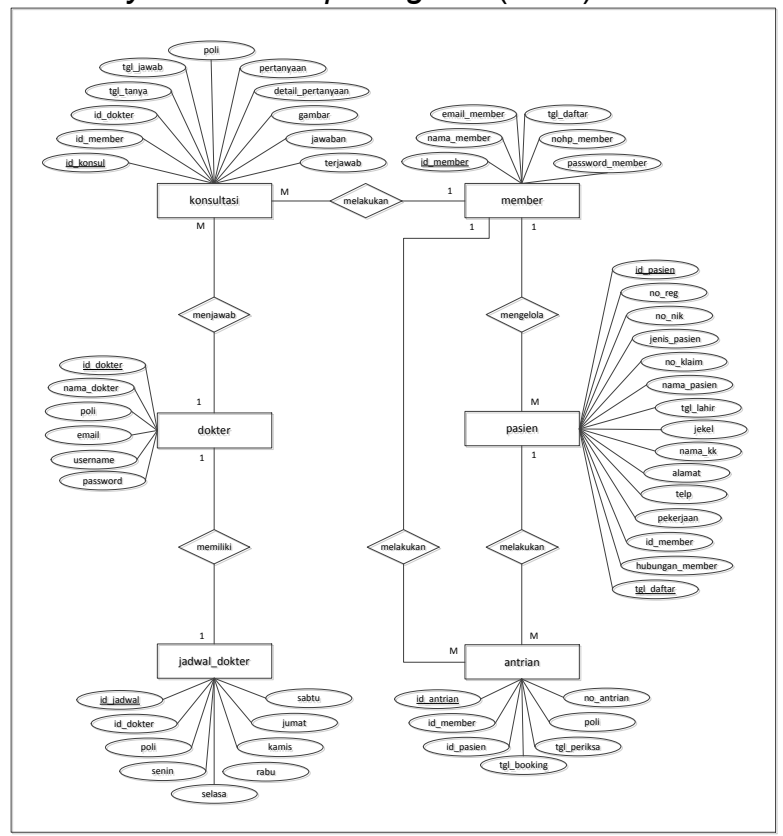

Gambar 4. Entity Relationship Diagram (ERD)

\section{Logical Record Structure (LRS)}

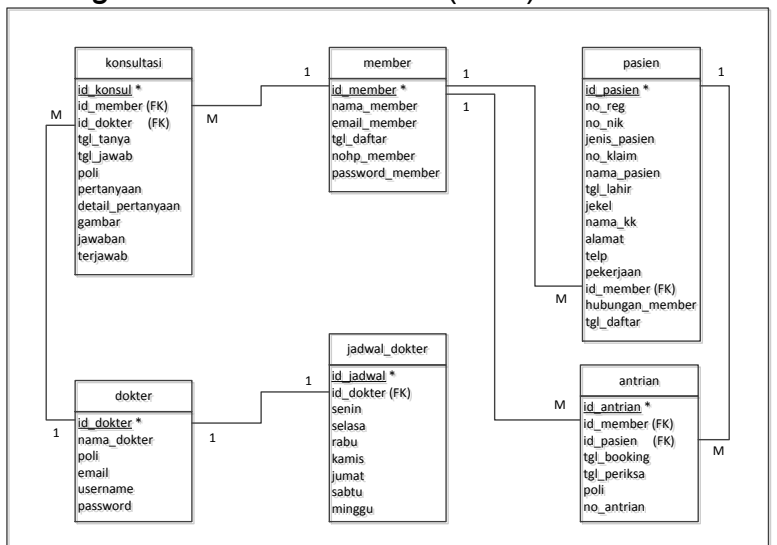

Gambar 5. Logical Record Structure (LRS)

6. Sequence Diagram Dokter

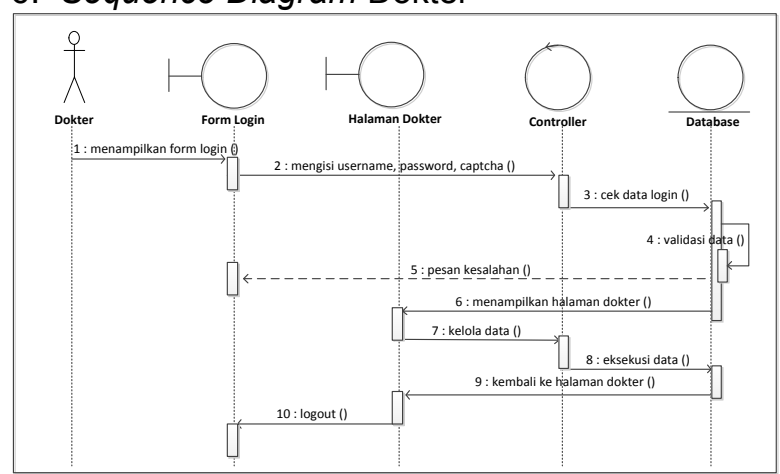

Gambar 6. Sequence Diagram Dokter 


\section{Component Diagram Member}

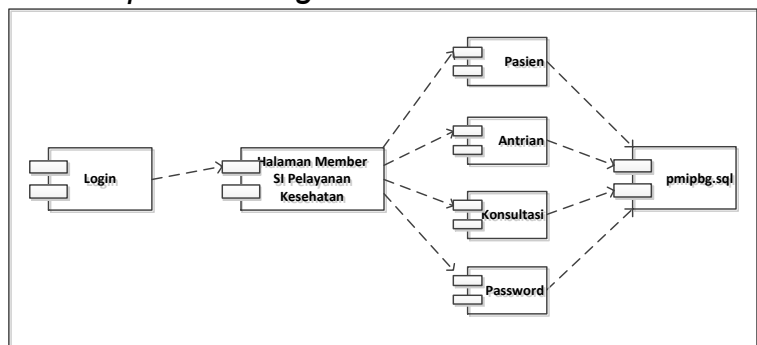

Gambar 7. Component Diagram Member

\section{Deployment Diagram}

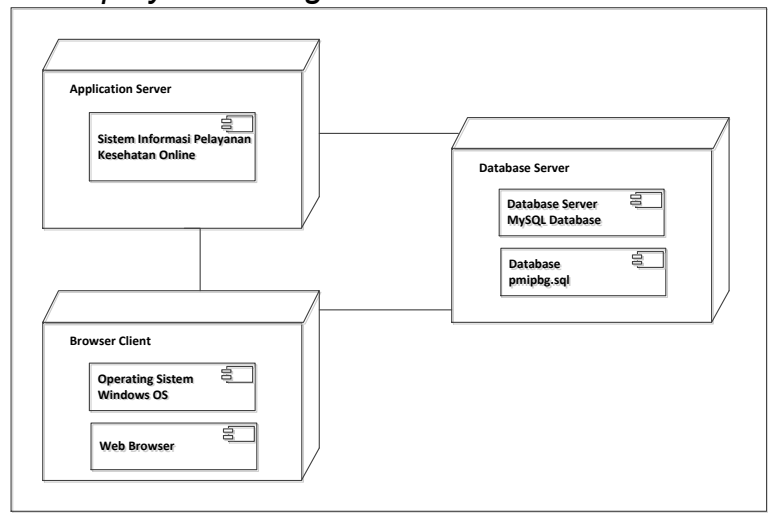

Gambar 8. Deployment Diagram

9. Implementasi Web

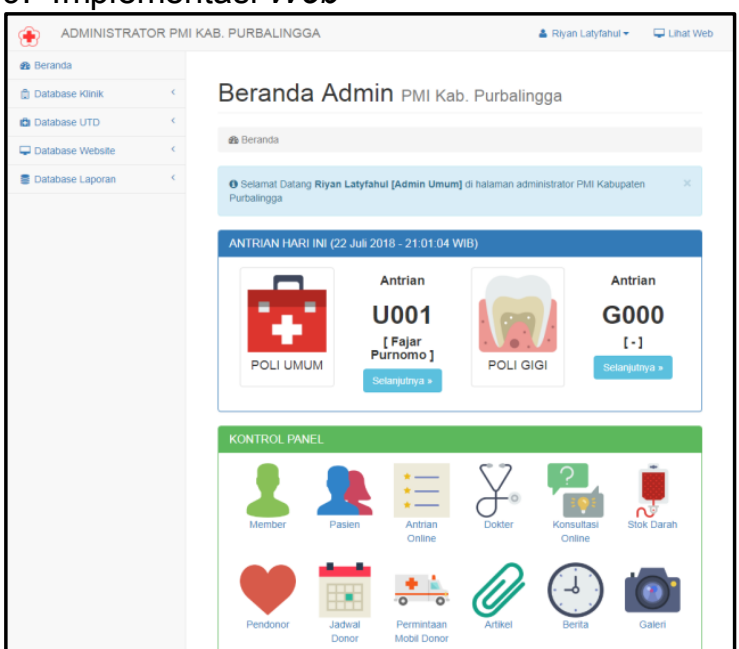

Gambar 9. Halaman Beranda Admin

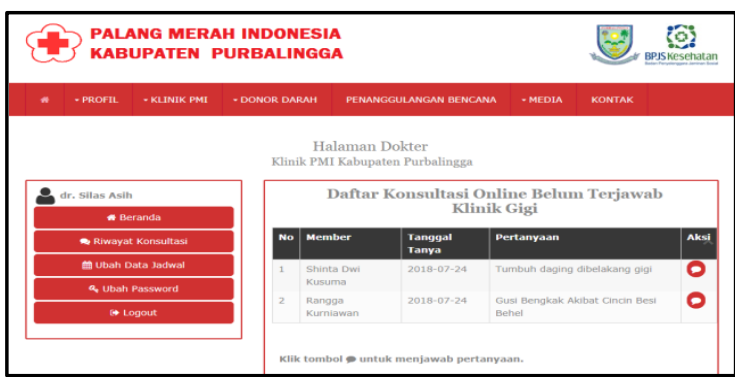

Gambar 10. Halaman Beranda Dokter

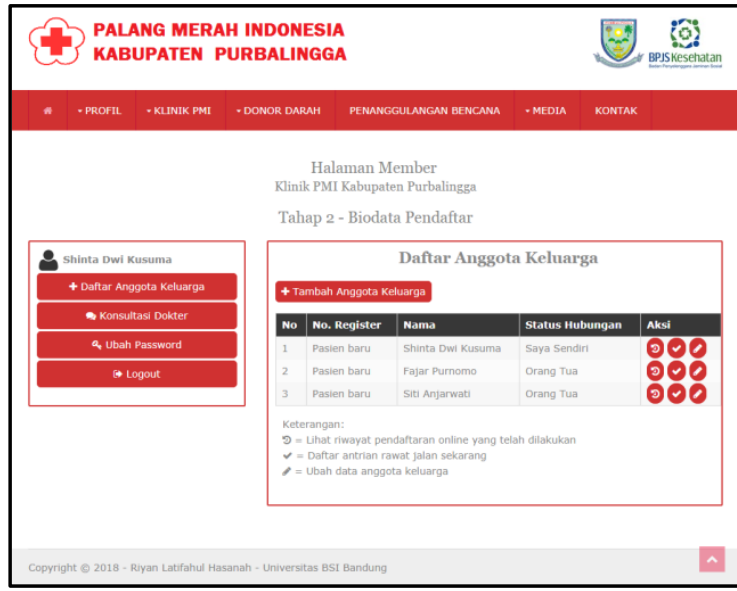

Gambar 11. Halaman Beranda Member

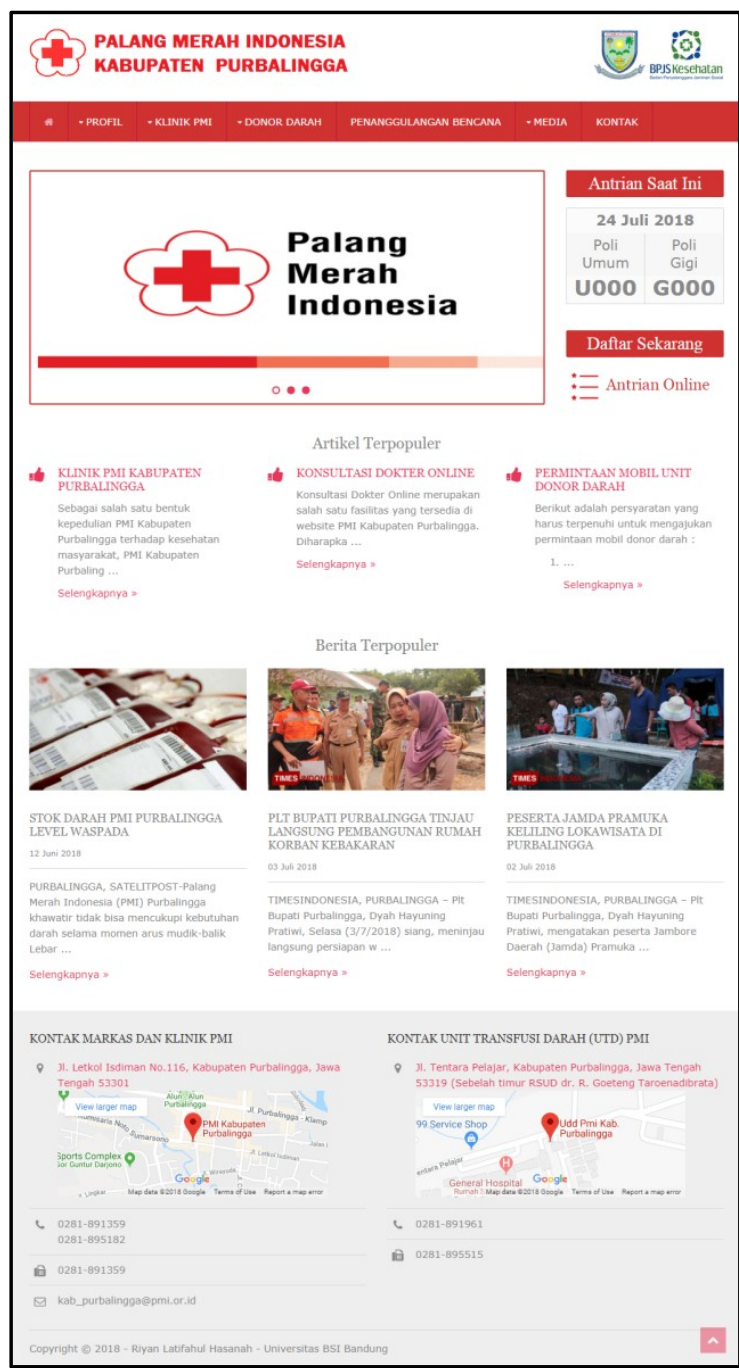

Gambar 12. Halaman Beranda Pengunjung 
10. Testing

a. Black box testing halaman login member

Tabel 3. Black Box Testing Halaman Login Member

\begin{tabular}{|c|c|c|c|c|c|}
\hline No & $\begin{array}{c}\text { Skenario } \\
\text { Pengujian }\end{array}$ & Test Case & $\begin{array}{l}\text { Has il yang } \\
\text { Diharapk an }\end{array}$ & $\begin{array}{c}\text { Has il } \\
\mathrm{Pe} \\
\text { ngujian }\end{array}$ & $\begin{array}{l}\text { Kesim- } \\
\text { pulan }\end{array}$ \\
\hline 1. & $\begin{array}{l}\text { Username, } \\
\text { password, den } \\
\text { kode captcha } \\
\text { tidgk disi, } \\
\text { kemudian klik } \\
\text { login }\end{array}$ & $\begin{array}{l}\text { Username: } \\
\text { (kosong) } \\
\text { Password: } \\
\text { (kosong) } \\
\text { Captcha: } \\
\text { (kosong) }\end{array}$ & $\begin{array}{l}\text { Sistem menolak } \\
\text { akses halaman } \\
m \text { en ber, lalu } \\
\text { tampil "Please fill } \\
\text { out this field" } \\
\text { pada is ian } \\
\text { usemame }\end{array}$ & $\begin{array}{l}\text { Sesuai } \\
\text { harapan }\end{array}$ & Valid \\
\hline 2 & $\begin{array}{l}\text { Salsh satu } \\
\text { kolom isian } \\
\text { tidak disi, } \\
\text { kemudian klik } \\
\text { login }\end{array}$ & $\begin{array}{l}\text { Username: } \\
\text { (diisi) } \\
\text { Password: } \\
\text { (diisi) } \\
\text { Captcha: } \\
\text { (kosong) }\end{array}$ & $\begin{array}{l}\text { Sistem menolak } \\
\text { akses halaman } \\
m \text { em ber, lalu } \\
\text { tampil "Please fill } \\
\text { out this field" } \\
\text { pada is ian yang } \\
\text { kosong } \\
\end{array}$ & $\begin{array}{l}\text { Sesuai } \\
\text { harapan }\end{array}$ & Valid \\
\hline 3. & $\begin{array}{l}\text { Mengisi benar } \\
\text { pada } \\
\text { usemame dan } \\
\text { password, } \\
\text { salah pada } \\
\text { kode captcha, } \\
\text { kemudian klik } \\
\text { login }\end{array}$ & $\begin{array}{l}\text { Username: } \\
\text { (benar) } \\
\text { Password: } \\
\text { (benar) } \\
\text { Captcha: } \\
\text { (salah) }\end{array}$ & $\begin{array}{l}\text { Sistem menolak } \\
\text { akses halaman } \\
\text { m em ber, lalu } \\
\text { tampil pesan } \\
\text { "Kode Captcha } \\
\text { yang Diinputkan } \\
\text { Salah" }\end{array}$ & $\begin{array}{l}\text { Sesuai } \\
\text { harapsn }\end{array}$ & Valid \\
\hline 4. & $\begin{array}{l}\text { Mengisi i salah } \\
\text { pada } \\
\text { usemmame den } \\
\text { password, } \\
\text { benar pada } \\
\text { kode captcha. } \\
\text { kemudian klik } \\
\text { login }\end{array}$ & $\begin{array}{l}\text { Username: } \\
\text { (salah) } \\
\text { Password: } \\
\text { (salah) } \\
\text { Captcha: } \\
\text { (bener) }\end{array}$ & $\begin{array}{l}\text { Sistem menolak } \\
\text { akses halaman } \\
\text { m em ber, lalu } \\
\text { tampil pesan } \\
\text { "Mas Usemame } \\
\text { Atau Password } \\
\text { Salah" }\end{array}$ & $\begin{array}{l}\text { Sesuai } \\
\text { harapsn }\end{array}$ & Valid \\
\hline 5. & $\begin{array}{l}\text { Mengisi benar } \\
\text { pada semus } \\
\text { isian, } \\
\text { kemudian klik } \\
\text { login }\end{array}$ & $\begin{array}{l}\text { Username: } \\
\text { (benar) } \\
\text { Passurd: } \\
\text { (benar) } \\
\text { Captcha : } \\
\text { (bengr) }\end{array}$ & $\begin{array}{l}\text { Sistem menerima } \\
\text { akses halaman } \\
\text { m em ber dan } \\
\text { tampil halamen } \\
\text { m em ber }\end{array}$ & $\begin{array}{l}\text { Sesuai } \\
\text { harapan }\end{array}$ & Valid \\
\hline
\end{tabular}

b. Black box testing halaman tambah anggota keluarga

Tabel 4. Black Box Testing Halaman Tambah Anggota Keluarga

\begin{tabular}{|c|c|c|c|c|c|}
\hline No & $\begin{array}{l}\text { Skenario } \\
\text { Pengujian }\end{array}$ & Teet Case & $\begin{array}{l}\text { Has il yang } \\
\text { Diharapk an }\end{array}$ & $\begin{array}{c}\text { Has il } \\
\mathrm{Pe} \\
\text { nguiian }\end{array}$ & $\begin{array}{l}\text { Kesim- } \\
\text { pulan }\end{array}$ \\
\hline 1. & $\begin{array}{l}\text { Mengos ongka } \\
n \text { isian yang } \\
\text { bertanda } \\
\text { bintang. } \\
\text { kemudian klik } \\
\text { simpan }\end{array}$ & \begin{tabular}{|l|} 
Ada isian \\
bertanda \\
bintang yang \\
dik os ongk an
\end{tabular} & $\begin{array}{l}\text { Sistem menolak } \\
\text { akses s impan, } \\
\text { lalu tampil pesan } \\
\text { per ingatan pada } \\
\text { is ian bertanda } \\
\text { bintang yang } \\
\text { kosong } \\
\end{array}$ & $\begin{array}{l}\text { Sesuai } \\
\text { harapan }\end{array}$ & Valid \\
\hline 2. & $\begin{array}{l}\text { Mengisikan } \\
\text { huruf pada } \\
\text { isian NIK dan } \\
\text { nomor telepon, } \\
\text { kemudian klik } \\
\text { simpan }\end{array}$ & $\begin{array}{l}\text { NIK: (diisi } \\
\text { huruf) } \\
\text { No. telepon: } \\
\text { (diisi huruf) }\end{array}$ & $\begin{array}{l}\text { Isian NIK dan } \\
\text { nomor telepon } \\
\text { menolak inputan } \\
\text { huruf, lalu } \\
\text { menghapus isi } \\
\text { is ian }\end{array}$ & $\begin{array}{l}\text { Sesugi } \\
\text { harspan }\end{array}$ & Valid \\
\hline 3. & $\begin{array}{l}\text { Mengis ì an } \\
\text { angka pada } \\
\text { is ian nama } \\
\text { lengk ap dan } \\
\text { nama KK. } \\
\text { kemudian klik } \\
\text { simpan }\end{array}$ & $\begin{array}{l}\text { Nama lengkap: } \\
\text { (diisi angk a) } \\
\text { Nama KK: (diisi } \\
\text { angka) }\end{array}$ & $\begin{array}{l}\text { Is ian nama } \\
\text { lengkap dan } \\
\text { nama KK } \\
\text { menolak inputan } \\
\text { angka, lalu } \\
\text { menghapus isi } \\
\text { is ian }\end{array}$ & $\begin{array}{l}\text { Sesuai } \\
\text { harapan }\end{array}$ & Valid \\
\hline 4. & $\begin{array}{l}\text { Mengisi } \\
\text { lengk ap pada } \\
\text { isian bertanda } \\
\text { bintang dan } \\
\text { benar pada } \\
\text { seluruh isian, } \\
\text { kemudian klik } \\
\text { simpan } \\
\end{array}$ & \begin{tabular}{|l|} 
Sian bertanda \\
bintang: (diisi) \\
NIK dan no. \\
Telepon: \\
(angk a) \\
Nama lengkap \\
dan nama KK: \\
(huruf) \\
\end{tabular} & $\begin{array}{l}\text { Sistem menerima } \\
\text { akses s impan } \\
\text { data, Islu data } \\
\text { ters impan }\end{array}$ & $\begin{array}{l}\text { Sesuai } \\
\text { harapan }\end{array}$ & Valid \\
\hline
\end{tabular}

c. Black box testing halaman pendaftaran antrian online

Tabel 5. Black Box Testing Halaman Pendaftaran Antrian Online

\begin{tabular}{|c|l|l|l|l|l|}
\hline No & \multicolumn{1}{|c|}{$\begin{array}{c}\text { Skenario } \\
\text { Pengujian }\end{array}$} & Teet Case & \multicolumn{1}{|c|}{$\begin{array}{c}\text { Hasil yang } \\
\text { Diharapk an }\end{array}$} & $\begin{array}{c}\text { Has il } \\
\text { Pe } \\
\text { ngujian }\end{array}$ & $\begin{array}{c}\text { Kesim- } \\
\text { pulan }\end{array}$ \\
\hline 1. & $\begin{array}{l}\text { Mengosongka } \\
\text { n semua stau } \\
\text { salah satu } \\
\text { isian, } \\
\text { kemudian klik } \\
\text { simpan }\end{array}$ & $\begin{array}{l}\text { Semus atau } \\
\text { salah satu is ian } \\
\text { dik os ongk an }\end{array}$ & $\begin{array}{l}\text { Sistem menolak } \\
\text { akses s impan, } \\
\text { Islu tampil pesan } \\
\text { peringatan pada } \\
\text { is ian yang kos ong }\end{array}$ & $\begin{array}{l}\text { Sesuai } \\
\text { harapan }\end{array}$ & Valid \\
& & & \\
\hline
\end{tabular}

\begin{tabular}{|c|c|c|c|c|c|}
\hline 2 & $\begin{array}{l}\text { Mengisi } \\
\text { tanggal } \\
\text { periksa } \\
\text { dengan } \\
\text { tanggal hari ini } \\
\text { stau dengan } \\
\text { tangal yang } \\
\text { sudah lewat, } \\
\text { kemudian klik } \\
\text { simpan }\end{array}$ & $\begin{array}{l}\text { Tanggal periks a } \\
\text { : (diisi tanggal } \\
\text { hari ini atau } \\
\text { tanggal yang } \\
\text { sudan lewat) } \\
\text { Poli : (diisi) }\end{array}$ & \begin{tabular}{|l|} 
Sistem menolak \\
akses s impan, \\
lalu tampil pesan \\
"Mohon masf, \\
pendsftaran \\
antrian minimal \\
s atu harisebelum \\
tanggal periksa / \\
tanggal yang \\
dipilih sudah \\
lewat" \\
\end{tabular} & $\begin{array}{l}\text { Sesuai } \\
\text { harspan }\end{array}$ & Valid \\
\hline 3. & $\begin{array}{l}\text { Mengisi } \\
\text { tanggal } \\
\text { periksa } \\
\text { dengan } \\
\text { tanggal yang } \\
\text { melebihi satu } \\
\text { minggu } \\
\text { kedepan, } \\
\text { kemudian klik } \\
\text { simpan } \\
\end{array}$ & $\begin{array}{l}\text { Tanggal periks a } \\
\text { : (disi tanggal } \\
\text { yang melebihi } \\
\text { satu minggu } \\
\text { kedepan) } \\
\text { Poli : (diisi) }\end{array}$ & \begin{tabular}{|l|} 
Sistem menolak \\
akses s impan, \\
Islu tampil pesan \\
"Mohon magf, \\
pendiaftaran \\
antrian maks imal \\
untuk satu \\
minggu ke depan"
\end{tabular} & $\begin{array}{l}\text { Sesuai } \\
\text { harspan }\end{array}$ & Valid \\
\hline 4. & $\begin{array}{l}\text { Mengisi } \\
\text { lengks ap dan } \\
\text { benar pada } \\
\text { semua is ian, } \\
\text { kemudian klik. } \\
\text { simpan }\end{array}$ & $\begin{array}{l}\text { Tanggal periksa } \\
\text { : (diisi benar) } \\
\text { Poli : (diisi) }\end{array}$ & $\begin{array}{l}\text { Sistem menerima } \\
\text { akses s impan } \\
\text { data, lalu data } \\
\text { ters impan }\end{array}$ & $\begin{array}{l}\text { Sesuai } \\
\text { harapan }\end{array}$ & Valid \\
\hline
\end{tabular}

d. Black box testing halaman ubah password

Tabel6. Black Box Testing Halaman Ubah

\section{Password}

\begin{tabular}{|c|c|c|c|c|c|}
\hline No & $\begin{array}{c}\text { Skenario } \\
\text { Pengujian }\end{array}$ & Test Case & $\begin{array}{l}\text { Has il yang } \\
\text { Diharapk an }\end{array}$ & $\begin{array}{c}\text { Has il } \\
\text { Pe } \\
\text { ngujian }\end{array}$ & $\begin{array}{l}\text { Kesim- } \\
\text { pulan }\end{array}$ \\
\hline 1. & $\begin{array}{l}\text { Mengos ongks } \\
\text { n semua atau } \\
\text { salah satu } \\
\text { is isn, } \\
\text { kemudian klik } \\
\text { simpan }\end{array}$ & $\begin{array}{l}\text { Semua atau } \\
\text { salah satu isian } \\
\text { dik os ongk an }\end{array}$ & \begin{tabular}{|l|} 
Sistem menolak \\
per ubahan \\
password, lalu \\
tampil "Please fill \\
out this field" \\
pada is ian yang \\
kosong
\end{tabular} & $\begin{array}{l}\text { Sesuai } \\
\text { harapan }\end{array}$ & Valid \\
\hline 2. & $\begin{array}{l}\text { Password } \\
\text { lama diis i } \\
\text { s salah, } \\
\text { password baru } \\
\text { dan ulangi } \\
\text { password disi } \\
\text { sama, } \\
\text { kemudian klik } \\
\text { simpan }\end{array}$ & $\begin{array}{l}\text { Password lama: } \\
\text { (salah) } \\
\text { Password baru: } \\
\text { (sama) } \\
\text { Ulangi password } \\
\text { : (sama) }\end{array}$ & \begin{tabular}{|l|} 
Sistem menolak \\
per ubahan \\
password, lalu \\
tampil pesan \\
"Password lama \\
yang diinputkan \\
s alah"
\end{tabular} & $\begin{array}{l}\text { Sesuai } \\
\text { harappan }\end{array}$ & Valid \\
\hline 3. & $\begin{array}{l}\text { Password } \\
\text { lama disi } \\
\text { benar. } \\
\text { password baru } \\
\text { dan ulangi } \\
\text { password disi } \\
\text { berbeds, } \\
\text { kemudian klik } \\
\text { simpan }\end{array}$ & $\begin{array}{l}\text { Password lama: } \\
\text { (benar) } \\
\text { Password baru: } \\
\text { (berbeda) } \\
\text { Ulangi password } \\
\text { :(ber beda) }\end{array}$ & $\begin{array}{l}\text { Sistem menolak } \\
\text { perubahan } \\
\text { password, lalu } \\
\text { tampil pesan } \\
\text { "Password baru } \\
\text { yang diinputkan } \\
\text { ber beda" }\end{array}$ & $\begin{array}{l}\text { Sesuai } \\
\text { harapan }\end{array}$ & Valid \\
\hline 4. & $\begin{array}{l}\text { Password } \\
\text { lams diis i } \\
\text { benar. } \\
\text { password baru } \\
\text { dan ulangi } \\
\text { password disi } \\
\text { sams, } \\
\text { kemudian klik } \\
\text { simpan }\end{array}$ & $\begin{array}{l}\text { Password lama: } \\
\text { (benar) } \\
\text { Password baru: } \\
\text { (sama) } \\
\text { Ulangi password } \\
\text { :(sama) }\end{array}$ & $\begin{array}{l}\text { Sistem menerims } \\
\text { perubahan } \\
\text { password, lalu } \\
\text { tampil pesan } \\
\text { "Password } \\
\text { berhasil diubah. } \\
\text { Silakan login } \\
\text { kembali" dan } \\
\text { tampil halaman } \\
\text { login }\end{array}$ & $\begin{array}{l}\text { Sesuai } \\
\text { harapan }\end{array}$ & Valid \\
\hline
\end{tabular}

\section{Publikas Web}

Sebagai bentuk implementasi, website yang telah dibuat harus dipublikasikan agar dapat diakses oleh masyarakat luas melalui media internet. Publikasi website dilakukan dengan membeli domain dan hosting sebagai jasa penyewaan tempat di internet. Penulis melakukan pembelian domain dan hosting di 
situs www.indoreg.co.id dengan alamat domain pmi-purbalingga.web.id.

\section{E. KESIMPULAN DAN SARAN}

1. Kesimpulan

a. Sistem informasi pelayanan kesehatan online berbasis web ini memberikan informasi yang lengkap kepada masyarakat mengenai kegiatan dan pelayanan kesehatan di PMI Kabupaten Purbalingga.

b. Kehadiran website ini memberikan kemudahan dalam memperoleh nomor antrian pendaftaran bagi calon pasien yang akan melakukan kunjungan rawat jalan di klinik PMI Kabupaten Purbalingga.

c. Informasi stok darah terkini serta prosedur permintaan darah yang ditampilkan di website sangat membantu masyarakat yang membutuhkan.

d. Fasilitas website seperti konsultasi dokter online, formulir online calon pendonor serta formulir online permintaan mobil donor darah menjadi nilai tambah pelayanan di PMI Kabupaten Purbalingga.

e. Kehadiran website merupakan sarana untuk meningkatkan hubungan dan komunikasi dengan masyarakat sehingga diharapkan dapat menjadi pendukung pelaksanaan visi PMI yaitu PMI yang dicintai masyarakat.

\section{Saran-saran}

Agar website yang telah dibuat dapat berjalan secara optimal, maka penulis memberikan saran sebagai berikut:

a. Dibutuhkan administrator pada bidang klinik, bidang unit transfusi darah dan bidang markas untuk mengolah data pada masing-masing bidang tersebut.

b. Baik administrator maupun dokter harus mengecek akunnya secara berkala agar mengetahui informasi terbaru mengenai aktifitas website yang dilakukan pengunjung ataupun member.

c. Perlunya peningkatan keamanan website dan pemeliharaan data dengan melakukan back up data secara berkala.

d. Dalam penelitian selanjutnya diharapkan website inidapat disempurnakan, seperti penambahan fitur untuk mengelola prosedur pelayanan di klinik mulai dari pendaftaran hingga pasien selesai berobat.

\section{DAFTAR PUSTAKA}

[1] Dermawan, Juniardi. dan Sari Hartini. 2017. Implementasi Model Waterfall pada Pengembangan Sistem Informasi Perhitungan Nilai Mata Pelajaran Berbasis Web pada Sekolah Dasar Al-Azhar Syifa Budi Jatibening. ISSN: 2579-3500. Jakarta: Paradigma Vol. 19, No. 2, September 2017: 142-147. Diambil dari: http://ejournal.bsi.ac.id/jurnal/index.php/par adigma/article/view/2131/1707. (23 April 2018)

[2] Josi, Ahmat. 2016. Implementasi Framwork Boostrap Pada Website STMIK Prabumulih. ISSN: 2088-3943. Prabumulih: Jurnal Mantik Penusa Vol. 20, No. 1, Desember 2016: 1-4. Diambil dari: http://ejurnal.pelitanusantara.ac.id/index.php/manti k/article/viewFile/204/116. (24 April 2018)

[3] Junianto, Erfian. dan Yusa Primaesha. 2015. Perancangan Sistem Tracking Invoice Laboraturium Pada PT Sucufindo (Persero) Bandung. ISSN: 2355-6579. Bandung: Informatika Vol. 2, No. 2, September 2015: 442-452. Diambil dari: http://ejournal.bsi.ac.id/jurnal/index.php/ji/ar ticle/view/133/107. (23 April 2018)

[4] Mujiati, Hanik dan Sukadi. 2016. Analisis Dan Perancangan Sistem Informasi Stok Obat Pada Apotek Arjowinangun. ISSN: 2338-9761. Pacitan: Bianglala Informatika Vol. 4, No. 1, Maret 2016: 11-15. Diambil dari:

http://ejournal.bsi.ac.id/jurnal/index.php/Bia nglala/article/view/536/428. (23 April 2018)

[5] Purnama, Vichi Chandra dan Noor Hasan. 2016. Perancangan Sistem Informasi Inventori Darah Berbasis Web Pada Palang Merah Indonesia Cabang Bantul. ISSN: 2088-0154. Yogyakarta: Journal Speed Sentra Penelitian Engineering dan Edukasi Vol. 8, No. 3: 35-41. Diambil dari: http://ejurnal.net/portal/index.php/speed/arti cle/view/1316. (18 April 2018)

[6] Rahmayu, Mulia. 2015. Rancang Bangun Sistem Informasi Nilai Ujian Siswa SMP Negeri 3 Bumiayu Berbasis Web. Jakarta Barat: Khatulistiwa Informatika Vol. 3, No. 2, Desember 2015: 159-168. Diambil dari: http://ejournal.bsi.ac.id/ejurnal/index.php/kh atulistiwa/article/view/1663/1. (2 Mei 2017)

[7] Rahmayu, Mulia. 2016. Rancang Bangun 
Sistem Informasi Pada Rumah Sakit Dengan Layanan Intranet Menggunakan Metode Waterfall. ISSN: 2338-8161. Jakarta: Evolusi Vol. 4, No. 2: 33-40. Diambil dari: http://ejournal.bsi.ac.id/jurnal/index.php/evol usi/article/view/699/574. (23 April 2018)

[8] Raja, B. Hendro P. Manik, Arif B. Putra N. dan M. Azhar Irwansyah. 2015. Rancang Bangun Sistem Informasi Geografis Berbasis Web Fasilitas Pelayanan Kesehatan di Kota Pontianak. Tanjungpura: Jurnal Edukasi dan Penelitian Informatika (JEPIN) Vol. 1, No. 2: 64-71. Diambil dari: http://jurnal.untan.ac.id/index.php/jepin/artic le/view/10520/11921. (25 April 2018)

[9] Setiyawati, Erwin dan Sardiarinto. 2016. Perancangan Sistem Informasi Berbasis Web Studi Kasus: KSU BMT Al-lkhwan Yogyakarta. Yogyakarta: Indonesian Journal on Computer and Information Technology Vol. 1, No. 1 Mei 2016: 34-41. Diambil dari: http://ejournal.bsi.ac.id/jurnal/index.php/ijcit/ article/view/417/317. (23 April 2018)

[10] Suharsana, I Ketut, IGP Wirarama Wedashwara Wirawan dan Ni Luh Ayu KartikaYuniastari S. 2016. Implementasi Model View Controller Dengan Framework Codeigniter Pada ECommerce Penjualan Kerajinan Bali. Denpasar: Jurnal Sistem Dan Informatika Vol. 2, No. 1, November 2016: 19-28. Diambil dari: https://media.neliti.com/media/publication s/130604-ID-implementasi-model-viewcontroller-denga.pdf. (24 April 2018)

[11] Sundari, Jenie. 2016. Sistem Informasi Pelayanan Puskesmas Berbasis Web. ISSN: 2461-0690. Jakarta: IJSE Indonesian Journal on Software Engineering Vol. 2, No. 1: 44-49. Diambil dari:

http://ejournal.bsi.ac.id/jurnal/index.php/ijs e/article/view/665/556. (18 April 2018)

[12] Syukron, Akhmad. dan Noor Hasan. 2015. Perancangan Sistem Informasi Rawat Jalan Berasis Web Pada Puskesmas Winog. ISSN: 2338-9761. Yogyakarta: Bianglala Informatika Vol. 3, No. 1, Maret 2015: 28-34. Diambil dari: http://ejournal.bsi.ac.id/jurnal/index.php/Bi anglala/article/view/574/465 . (18 April 2018)

[13] Taufik, Andi dan Ermawati. 2017. Perancangan Sistem Informasi Pemesanan Pentas Seni Berbasis Web Pada Sanggar Seni Getar Pakuan Bogor. ISSN: 2461-0690. Jakarta: IJSE Indonesian Journal on Software Engineering Vol. 3, No. 2: 1-7. Diambil dari:

http://ejournal.bsi.ac.id/jurnal/index.php/ijs e/article/view/2812/1836. (24 April 2018). 